\title{
Industry 4.0 an empirical analysis of users' intention in the automotive sector
}

\author{
Martina Toni, Maria Francesca Renzi, \\ Maria Giovina Pasca, Roberta Guglielmetti Mugion, \\ Laura di Pietro and Veronica Ungaro \\ Department of Business Studies, University Roma Tre, Rome, Italy
}

Automotive sector

Received 23 April 2020 Revised 7 August 2020 8 January 2021 Accepted 27 March 2021

\begin{abstract}
Purpose - This paper aims to study the automotive 4.0 context to understand the consumers' propensity towards high-tech automated cars. The paper analyses the antecedents that lead to the use of innovative vehicles. Theory of planned behaviour (TPB) is adopted and extended by including further constructs, such as environmental aspects and inhibitors.

Design/methodology/approach - The advent of smart technologies and the internet of things has given rise to several contributions that look at consumers' intention towards innovation adoption in the automotive industry. Furthermore, this study rises from the growing interest that sustainable mobility achieved. Based on the previous technology acceptance models and particularly TPB, this paper develops a structured questionnaire. After a pilot survey, the final questionnaire was administered online through email and social media in the Italian context. Structural equation modelling technique has been used for analysing data and testing the conceptual model.

Findings - The number of questionnaires filled out was 310, with a sample composed of young adults, characterised by different addiction levels towards technology. The results explain the drivers that lead to accept and adopt high-tech automated vehicles. This topic is still under investigation and offers potential research opportunities, considering the evolution of the market and the consumers' habits and needs. Future research studies in this area should focus on generalising the present findings in other countries. Moreover, once this technology starts to be adopted, other constructs could be discovered, investigated and included in the model.

Originality/value - Mobility has raised a growing interest with the fast increasing demand for sustainability and growth of innovative solutions embedded in mobility. This research explores the TPB model's application and the relation between its constructs, environmental aspects, inhibitors and intention to adopt automated vehicles. On this strength, it is possible to identify each construct's relevance for obtaining social consensus on the market.
\end{abstract}

Keywords Innovation, Sustainability, Mobility, High-tech car, Automated vehicles, Environment, Intention

Paper type Research paper

\section{Introduction}

The fourth industrial revolution is currently occurring and it was triggered by the development of information and communications technologies (ICT) with decentralised control and advanced connectivity (internet of things (IoT) functionalities).

(C) Martina Toni, Maria Francesca Renzi, Maria Giovina Pasca, Roberta Guglielmetti Mugion, Laura di Pietro and Veronica Ungaro. Published by Emerald Publishing Limited. This article is published under the Creative Commons Attribution (CC BY 4.0) licence. Anyone may reproduce, distribute, translate and create derivative works of this article (for both commercial and non-commercial purposes), subject to full attribution to the original publication and authors. The full terms of this licence may be seen at http://creativecommons.org/licences/by/4.0/legalcode

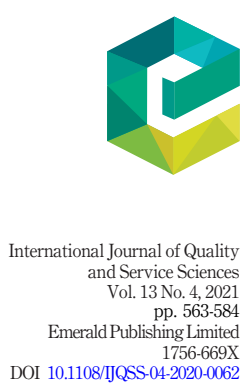


IJQSS

13,4

Growing attention is being paid to the implications of integrating Io $\mathrm{T}$ and services technologies into industrial value creation. This new paradigm of digitised and connected manufacturing is referred to as "Industry 4.0" and its smart and autonomous production (Arnold et al., 2016). It enables real-time-capable Internet-based connectedness of people, machines and objects, as well as information and communication technologies for the dynamic management of complex business processes (Bauer et al., 2015). Industry 4.0 activates ready access to data and information on an unprecedented scale (Beard-Gunter et al., 2019).

According to Bauernhansl et al. (2016), Industry 4.0 factory could result in the decrease of production costs (by 10-30\%), logistic costs (by 10-30\%) and quality management costs (by $10-20 \%$ ). However, service innovation is not only related to service productivity. Indeed, innovation can address customers' unmet needs, enhancing their service quality assessment (Parasuraman, 2010). The industry 4.0 approach integrates the business and manufacturing processes by combining all the actors (suppliers and customers) in the value chain. Hence, it represents an opportunity, at the industrial level, both for companies, for consumers and for every field where technology is required (Rojko, 2017). Industry 4.0 is based on embedded systems with decentralised control and advanced connectivity that collect and exchange realtime information to identify, locate, track, monitor and optimise the production processes. It handles a significant amount of data collected from the operations, machines and products. Typically, the data are stored in cloud storage. They require extensive analytics that leads from the "raw" data to the useful information and, finally, to the concrete actions that support an adaptive and continuously self-optimising industrial production process. In this regard, it can cause privacy and data protection problems, which may inhibit these innovative technologies.

Industry 4.0 is linked to "automation". The Oxford English Dictionary (OED) is described as "the use or introduction of automatic equipment in a manufacturing or other process or facility" to replace human labour. The Automotive sector is a relevant field of application, as it has undergone impressive transformations, such as smart cars equipped with sensors and autopilot (Rojoko, 2017). In this sector, the term "autonomous" has been applied to different automation levels that gradually eliminate or reduce the necessity of continuous monitoring by humans. Indeed, most autonomous systems require a driver to perform some specific task (Shladover, 2018).

The International Society of Automotive Engineers (SAE On-Road Automated Vehicle Standards Committee) (2018) defined six levels of automation from no driving automation (level 0) to full driving automation (level 5), divided into two parts: the human that monitors the driving environment (level $0=$ no automation, level $1=$ driver assistance, level $2=$ partial automation) and the automated systems that monitor the driving environment (level $3=$ conditional automation, level $4=$ high automation, level $5=$ full automation). These increasing automation levels require three primary actors in driving: the (human) user, the driving automation system and other vehicle systems and components.

The positive effects of Industry 4.0 are evident in terms of efficiency and new business models creation. The technological change and the advent of self-driving cars may have the potential to improve safety substantially, time and fuel efficiency and mobility in general (Beiker, 2012; Douma and Palodichuk, 2012; Silberg et al., 2012). Although from the users perspective, some risks could emerge concerning the loss of control of the vehicle and personal data utilisation. On this strength, as the diffusion of high-tech cars could positively impact society in terms of safety and environmental impacts (fuel/resource efficiency), it is relevant to understand how to increase the willingness to adopt these new technologies.

Prior studies on this topic commonly pay less attention to the users' attitudes and intention towards automated cars to judge perceived benefits and concerns (König and Neumayr, 2017). As it is still unknown what the key "drivers" or determinants of automated 
driving are, there is a need for more research on user acceptance or interest in this topic (Nielsen and Haustein, 2018). Hence, this study extends the theory of planned behaviour (TPB) applying it to automotive 4.0.

This research investigates the consumers' propensity towards high-tech automated cars. In this way, the paper analyses the antecedents that lead to the use of innovative vehicles by implementing and extending the TPB.

The paper is structured as follows. Section 2 presents the literature review, the research gaps and hypotheses. Section 3 offers the methodological approach, including the research plan, data collection and analysis. The results of our empirical study are presented in Section 4. Section 5 provides discussion and findings. Finally, Section 6 provides conclusions, future perspectives and managerial implications.

\section{Literature review}

This section examines the main aspects that are considered relevant to the purpose of this research. Hence, the literature review section explores the following topics concerning the context of this research: Industry 4.0 with its definition and applications; automotive sector and the transformation of transportation patterns due to technology; consumer behaviour providing insights about the consumer intention and behavioural models; after that the research model and hypotheses are presented. In the first two paragraphs, papers that study industry 4.0 and automotive from multiple perspectives have been included to obtain a broader view. In the last section, papers that analyse consumer behaviour (through the application of TPB) related to technology and mobility have been included. In this way, the literature review provides insights into the proposed research model.

\subsection{Industry 4.0}

Nowadays, the fourth industrial revolution is occurring. It was triggered by the development of ICT with its technological foundation in smart automation of cyber-physical systems enabled by decentralised control and advanced connectivity (IoT functionalities). This new paradigm of digitised and connected manufacturing is referred to as "Industry 4.0" characterised by its smart and autonomous production (Arnold et al., 2016), interoperability and connectivity; it allows a continuous flow of information between the devices and components, machine-to-machine interaction (M2M), manufacturing systems and actors.

The main idea of Industry 4.0 is the introduction of internet technologies into the industry, implying progress on threefold perspectives: digitisation of production, automation and Automatic Data Interchange (Almada-Lobo, 2016; Schlechtendahl et al., 2015).

Stages in industrial manufacturing systems from manual work towards Industry 4.0 concept leads to improved quality of life. As a result of this, the machines, products and factories can connect and communicate via the wireless network's Industrial IoT. In some cases, humans' role is essential, as Human-To-Machine (H2M) collaboration is necessary as some production tasks are fully automatised. In terms of data creation, the extensive usage of sensors and control systems in the industry generates huge data. Cyber-physical systems can be used to manage such a high volume of data is called Big Data. This amount of data needs to be addressed in a systematic way of acquiring and analysing them. Hence, by integrating resources, service systems develop new value propositions for customers (Gummesson et al., 2010) and, in this way, Industry 4.0 transforms a potential resource into a specific benefit. 
IJQSS

13,4

Industry 4.0 applies to many fields transforming cities, services and products through the so-called "smartification". The automotive industry is currently undergoing a potentially revolutionary change that affects the interaction between humans and machines and urban design in roads and cities (Silberg et al., 2012). The advent of automated cars could have beneficial effects on safety, time, fuel efficiency and mobility patterns (Beiker, 2012; Douma and Palodichuk, 2012; Silberg et al., 2012). However, the introduction of such radically new technology is surrounded by a high degree of uncertainty (Van Geenhuizen and Nijkamp, 2003). In particular, future implications could lead to two different scenarios: people preferring the ultimate level of autonomy through self-driving cars, to optimise their time while driving; people becoming dependent on technology entailing psychological consequences (König and Neumayr, 2017).

\subsection{Automotive}

Automotive 4.0 is at its inception but is going to be established in the next years. In particular, two emerging trends are transforming personal transportation: automated vehicles - A.V.s (self-driving or driverless cars) and on-demand mobility (car-sharing) competing with conventional transportation (private cars and public transit) (Greenblatt and Shaheen, 2015). These newest trends are enabled by technology, expected to replace human decision-making with computer algorithms. Some provisions conclude that transformative changes will affect personal transport and potentially nearly all vehicles will become autonomous by mid-century (Greenblatt and Shaheen, 2015). The self-driving car is an intelligent vehicle that transports people or objects to a specific predetermined target with the support of sensors, which guarantee perception of the path environment, information of the route to be covered and car control (Zhao et al., 2018; Baruch, 2016; Levinson et al., 2011; Walker et al., 2001).

Increasing global urbanisation is paving the way for the rise and expansion of Industry 4.0 (Pejic" Bach et al., 2013), as there is a need to renew and develop urban infrastructure to ensure their quality of life and sustainability (Etezadzadeh, 2015; Nahtigal and Bertoncelj, 2013). Indeed, Industry 4.0 is changing the relations between consumers, products and producers (Wynstra et al., 2015) through smart equipment that allows information about locations, demographic changes, resources, energetic efficiency and urban production (Heck and Rogers, 2014). Customers will adapt to smart product characteristics, although Begg (2014) states that the more sophisticated the level of automation, the more sceptical people become.

In the transportation sector, research attention is increasingly focussing on automated driving and its potential effects on transport behaviour and infrastructure (Nielsen and Haustein, 2018). Other studies have focussed on the likely impacts of automated driving on traffic flow and infrastructure performance in terms of delay and capacity (Aria et al., 2016; Department for Transport, 2016). The latter is because technology will collect and analyse data from the human environment to increase efficiency, services and mobility (Lasi et al., 2014). What concerns the assessment of behavioural responses to automated transport is weakly established and it results in difficulty forecasting future options that very few have experienced. In any case, the public's opinions towards automated or self-driving cars can indicate how the transformation towards automation could develop (Nielsen and Haustein, 2018).

People recognise the main potential benefits of technology, such as fewer crashes and better fuel economy, less congestion and short travel times. On the other hand, some concerns arise about safety issues related to errors in the system or equipment and privacy issues (Schoettle and Sivak, 2014; Beiker, 2012). Furthermore, other potential benefits are the 
more effective use of battery electric vehicles (BEVs), increased safety, more efficient road use, increased driver productivity and energy savings (Anderson et al., 2014; Folsom, 2012; Brown et al., 2014; Morrow et al., 2014; Troppe, 2014), improvements in air quality would also be significant because these technologies emitted no ozone-forming precursors, efficient traffic flow and decreased parking requirements (Greenblatt and Shaheen, 2015), safetyinduced light-weighting (Brown et al., 2014; Morrow et al., 2014). Hence, automotive 4.0 may also lead to improved energy use and environmental impacts.

Companies that introduce innovation need to consider and assess the double effects of

Automotive sector

innovation on both productivity and customers standpoint (Parasuraman, 2010). On this strength, users' involvement in knowledge sharing enables commitment, value co-creation and service innovation (Polese et al., 2019). As Guglielmetti Mugion et al. (2019) suggest in the car-sharing context, as the usage of high-tech cars is related to the use of technology, it is useful to refer to technology acceptance models. Some authors adopted models to assess acceptance, including the Technology Acceptance Model (Davis, 1989; Ghazizadek et al., 2012; Nordhoff et al., 2016). Multiple psychological, situational and socio-economic factors influence acceptance (Nordhoff et al., 2016) and gender, age, income, awareness of automation trends and level of autonomy in the current vehicle (Becker and Axhausen, 2017). Men and younger individuals result in more willingness to accept autonomous driving; higher incomes imply a higher willingness to pay; awareness of and experience with automation in vehicles also affects acceptance. Despite the potential benefits of automotive 4.0, the level of adoption depends on the users' characteristics, starting from the distinction between "moving" and "being moved" (Böhm et al., 2006, p. 4). Indeed, driving enthusiasts use to drive cars for pleasure, thus they might not be amongst the people adopting this new technology (Glancy, 2012) Thus, people that do not use public transportation do (Böhm et al., 2006, p. 4). There are also privacy issues, as people's daily driving needs to be tracked to make the system work (Song et al., 2010; Beiker, 2012; Silberg et al., 2012). Indeed, one of the most troubling aspects of the IoT is controlling the increasing data collected (Roman et al., 2013). The main question is how to ensure a sufficient privacy and security level that will prevent unauthorised access.

\subsection{Consumer behaviour}

As Buckley et al. (2018) state, with the advancements in automotive, it is timely to examine drivers' intended use of this technology type. Based on the most acknowledged models, according to the theory of reasoned actions (TRA) (Fishbein and Ajzen, 1975) and the TPB (Ajzen, 1991), the most crucial determinant of a person's behaviour is the intention to perform a behaviour. The intention is defined as a combination of attitude and subjective norm. Attitude towards a behaviour (usage of automated vehicles) is the degree to which the performance of that behaviour is positively or negatively valued. The Subjective norms construct defined as perceived social pressure to engage or not to engage in the behaviour. The main difference between the TRA and the TPB is the addition of a third variable: Perceived behavioural control that refers to people's perceptions of their ability to perform a behaviour. It is assumed to be a direct predictor of both intention and behaviour.

It has to be noted that the TRA model contains an element of indeterminacy (Bagozzi, 1992); indeed, as the author state, Attitude and Subjective norms have independent (compensatory) effects on intentions, with three possible causal outcomes: the only attitude influences the intentions, only Subjective norms influences the intentions or both Attitude and Subjective norms influence the intentions. However, it is impossible to control this trade-off between attitude and subjective norms in influencing the intention. This argument also applies to TPB that directly derives from the TRA model. Hence, there could be some 
IJQSS

13,4

specific conditions on the basis of which attitudes are able or not to influence intention and activate a behaviour. In the so-called "contingent consistency" (Liska, 1984; Andrews and Kandel, 1979; Susmilch et al., 1975; Liska, 1974; Acock and DeFleur, 1972; Warner and DeFleur, 1969) social and situational conditions can interact with attitude, in a way that the latter not necessarily influences the intentions. However, TPB is considered suitable in explaining mobility behaviour (Haustein and Hunecke, 2007). It contains the central predictors to explain mobility behaviour; then it comprises five parameters only; it can be easily and efficiently applied in the context of research. Moreover, the TPB is open to incorporating additional predictors to increase its predictive power (Haustein and Hunecke, 2007). It is tricky to measure it until the technology is available (Zmud et al., 2016).

When analysing an innovative context/application, user resistance to change is a crucial cause for many implementation problems (Jiang et al., 2000; König and Neumayr, 2017). This is since people regularly react with caution to innovation or even fight them in some cases (Goldenberg, Lehmann and Mazursky, 2001; Kemp et al., 1998). Recent studies show a more positive attitude of users towards self-driving technology; nevertheless, considerable resistance remains (Kyriakidis, Happee and De Winter, 2015; König and Neumayr, 2017). In literature, trust and perceived safety in the technology especially surfaced as influencing factors. Safety concerns were related to the performance of self-driving vehicles (Schoettle and Sivak, 2014), whereas trust is associated with data privacy and driving control (Kyriakidis, 2015; Howard and Dai, 2014).

\subsection{Research gap and hypotheses}

As consumers cover an essential role for the automotive 4.0 success (Van Geenhuizen and Nijkamp, 2003), the lack of empirical evidence from the user perspective needs to be filled. Indeed, current literature examines the research area regarding Industry 4.0 predominantly from a technical perspective (Kiel et al., 2017; Beier et al., 2017; Porter and Heppelmann, 2014) whereas as Beiker (2012, p. 1149) observes "beside the technology aspects of this field, questions regarding consumer acceptance remain". Consequently, this paper aims to fill the prevalent research gaps and to derive promising strategic implications for automotive 4.0.

This research aims at understanding the propensity towards high-tech automated cars, by extending the TPB (Ajzen, 1991) and adding two further drivers that are recurring in literature: inhibitors and environmental aspects. The research objective is because previous studies analysed this topic mainly from a technical and engineering perspective; thus this research aims to fill the gap due to the lack of studies that analyse this topic from the user perspective.

The TPB is one of the most acknowledged models in explaining intention and behaviour (Larue et al., 2015; Chen et al., 2007). The primary constructs (subjective norms, perceived behavioural control, attitude and intention) are all validated in the literature. Thus, its application is highly recognised in different contexts of human behaviour and technology acceptance (Buckley et al., 2018; Rahman et al., 2017; Oviedo-Trespalacios et al., 2019; Larue et al., 2015; Chen et al., 2007).

The TPB extends the TRA (Ajzen and Fishbein, 1980) to improve its predictive capability. Indeed, to explain behaviours not entirely under volitional control (Ajzen, 1987, 1991; Ajzen and Madden, 1986) introduced the TPB (Bagozzi, 1992), by adding the perceived behavioural control construct. In this way, as Bagozzi (1992) explains, TPB's behaviour differs from actions totally under voluntary control, as it is subject to interference by internal and external forces.

The dimensions included in the research model are the following: perceived behavioural control ("the person's belief as to how easy or difficult performance of the behaviour is likely 
to be"), subjective norms ("the degree to which an individual feels that most people who are important to him/her believe he/she should perform a particular behaviour"), attitude ("the degree to which a person has a favourable or unfavourable evaluation of performing the sector behaviour"), environmental aspects and Inhibitors. The first three are directly derived from theory and in particular from the TPB and the TRA. The latter (environmental factors and inhibitors) emerge from previous research. Automated car adoption implies environmental benefits (improved energy use and environmental impacts) and risks that could inhibit the adoption. In terms of services, automated vehicles' introduction is expected to reduce traffic congestion, energy consumption and environmental impacts (Kopelias et al., 2020; Milakis et al., 2017; Wadud et al., 2016; Brown et al., 2014). Based on previous literature, risks emerge in the adoption of automated vehicles from the user perspective, especially for what that concerns the potential danger for the driver, privacy issues and potential loss of control and distraction by the driver (Payre et al., 2014; Bezai et al., 2020; Hulse et al., 2018; Collingwood, 2017; Glancy, 2012; Taeihagh and Lim, 2019). Hence, the two new constructs have been added to understand whether the related awareness influences the intention of adopting automotive 4.0. The behaviour results are challenging to measure, as very few have experienced it (Nielsen and Haustein, 2018). Hence, this construct has not been included in the research. The complexity is due to the fact that a priori acceptability of technology consists of an evaluation of that technology before having any interaction with it, thus based on potential perceived usefulness and perceived ease of use (Davis, 1989); on the contrary technology, acceptance should include an evaluation of its usage or likely further possible usage (Bagozzi, 1981; Terrade et al., 2009).

Based on the previous literature, the research hypotheses have been proposed.

The following research hypotheses are presented (Figure 1):

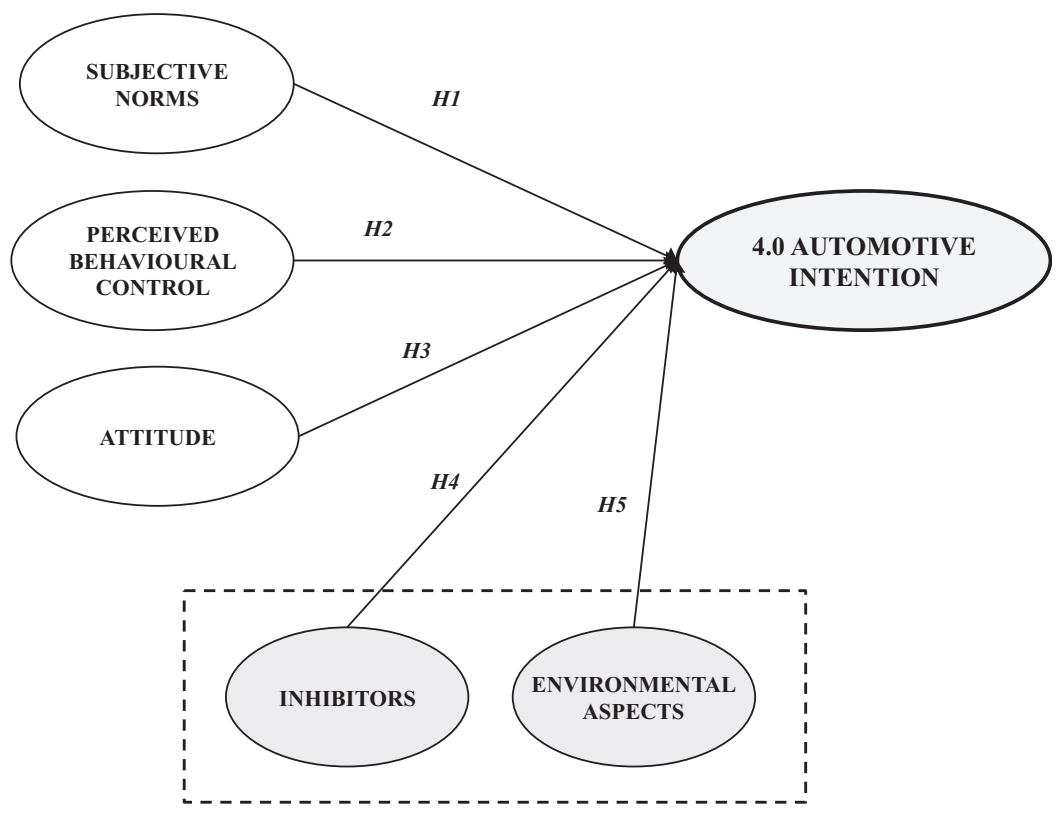

Figure 1. The proposed theoretical model 
IJQSS

13,4

H1. Subjective norms affect the intention to use an automated car.

H2. Perceived behavioural control affects the intention to use the automated car.

H3. Attitude affects the intention to use an automated car.

H4. Inhibitors affect the intention to use the automated car.

H5. Environmental aspects affect the intention to use an automated car.

In the proposed conceptual model, the intention to use an automated car is affected by five variables: subjective norms, perceived behavioural control, attitude, inhibitors and environmental aspects.

\section{Methodology}

Our study aims to understand the propensity towards automated cars by extending the TPB.

Based on acceptance models and literature review, a questionnaire was built through the integration of the existing models' constructs and adding two dimensions. These new constructs have been highlighted in literature: inhibitors and environment. The questionnaire was structured in six sections using a seven-point Likert scale (Malhotra, 1996) ( 1 = disagree; 7 = agree). It comprises the variables detected from the previous models and two additional sections aimed to measure the Inhibitors and Environmental aspects. The questionnaire was tested and adapted after a pilot survey on a sample of 30 respondents, during the period from October and December 2018.

The data has been analysed with descriptive and advanced statistics, using SPSS and Mplus software. The factors were extracted and defined using EFA and CFA and the model tested through structural equation modelling (SEM). A structural model was tested, based on TPB constructs. The factors of the model were extracted and defined through EFA and CFA and the relations amongst the variables were studied through the SEM, which is a spread modelling technique applied in social sciences to understand and explain relationships amongst the elements of a system (Reisinger and Turner, 1999; Yi et al.,2006).

In the quantitative approach, the TPB has been applied by including the following dimensions: subjective norms, perceived behavioural control, attitude and intention. As explained in the research design and hypotheses section, the behaviour has been not included in the research, as it results in difficulty measuring because very few have experienced it (Nielsen and Haustein, 2018). Two constructs have been included in the model that is: Inhibitor and Environment. Inhibitors include all the aspects related to risks, privacy issues, loss of control and distraction; Environmental aspects concern the respondents' opinions related to the relation between automated car innovation and environmental sustainability (i.e. technology as a source of environmental impacts reduction and environment protection).

\section{Results}

The questionnaire collected was 310 and the sample is composed of 310 respondents, of which $50.5 \%$ women and $49.5 \%$ men. The majority of the sample $(36.6 \%)$ is found in the $26-$ 35 and $18-25$ age groups $(32.0 \%)$. The respondents belong to the following age groups: $36-$ $45(13.9 \%), 46-55(9.7 \%), 56-65(6.8 \%)$ and over $65(1 \%)$. In total, $42.0 \%$ of the respondents have a high school level of education and $31.4 \%$ a bachelor degree. As shown in Table 1 , most of the sample consisted of students (35.9\%) and employees (34.9\%).

The analysis proceeds with factor analysis. 


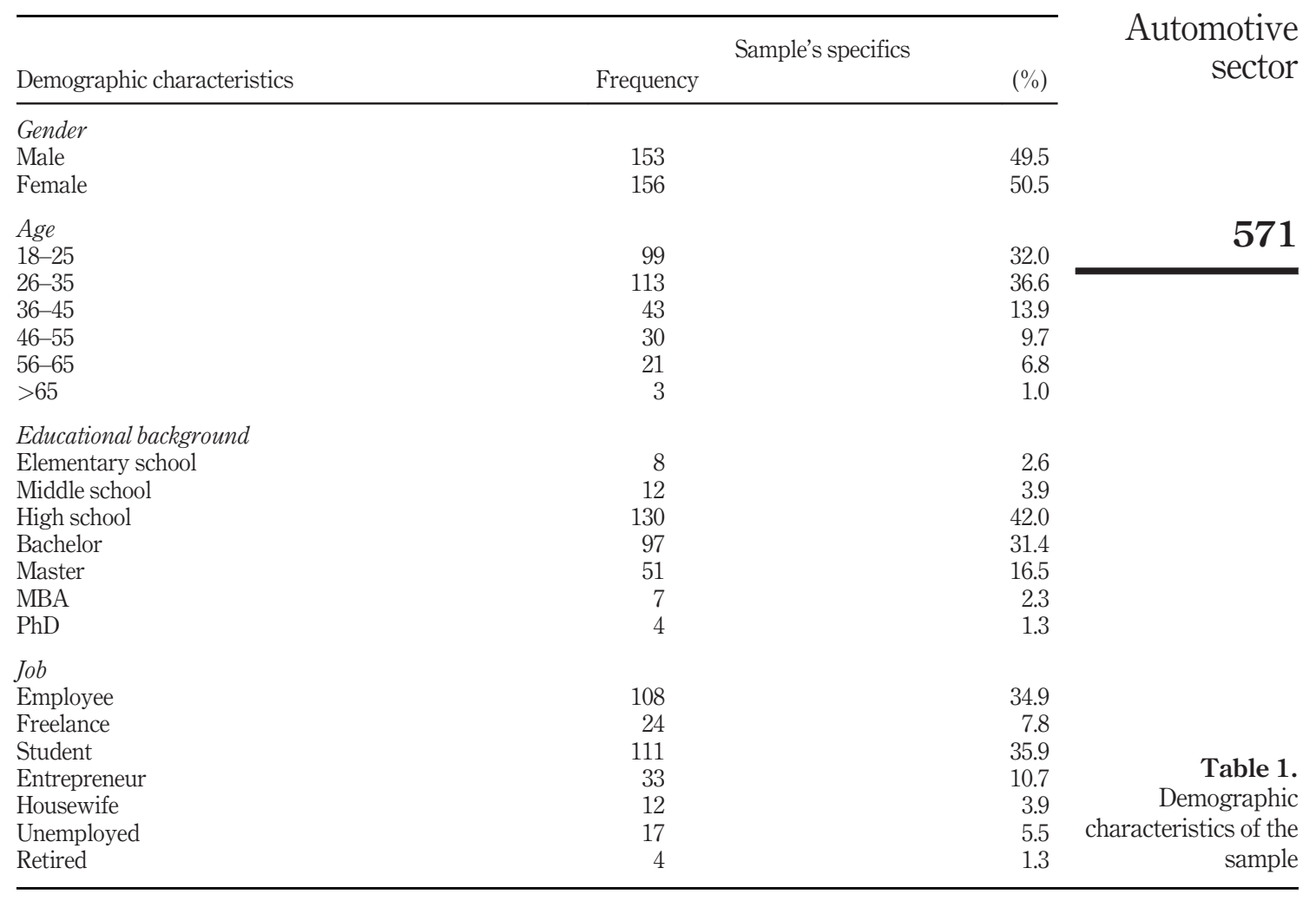

The proposed model is composed of TPB constructs and new dimensions that refer to the context of investigation: inhibitors and environmental aspects. TPB model has been already validated in literature, whereas the new dimensions need to be tested. A maximum likelihood method for parameter estimation was adopted and the internal reliability of each factor's scale was tested through the Cronbach's alpha coefficient (Cronbach, 1951) resulting in satisfactory (Nunnally, 1978).

The following tables show the reliability and validity of the constructs: Table 2 illustrates Cronbach's alpha values and Tables 3 shows the AVE and C.R. values (Fornell and Larcker, 1981) (Table 3) for each construct.

Following the internal consistency of each scale has been tested.

\begin{tabular}{lc}
\hline Constructs & Cronbach's alpha \\
\hline Social norms (SN) & 0.842 \\
Perceived behavioural control (PBC) & 0.785 \\
Attitude (ATT) & 0.8 \\
Inhibitors (IN) & 0.750 \\
Environmental aspects (ENV) & 0.845 \\
Intention (INT) & 0.877
\end{tabular}

Table 2. Cronbach's alpha 
IJQSS

13,4

572

All the data are above the thresholds considered adequate to affirm the reliability and validity of the constructs: 0.5 for AVE and 0.7 for C.R. (Fornell and Larcker, 1981).

Following the related EFA (Table 4) and CFA path diagram (Figure 2) for each factor are illustrated. The practical significance of all the factor loadings is observed $(>0.4)$ by following the cut-off criteria existing in the literature (Hair et al., 1998; Stevens, 1992). Indeed, Hair et al. (1998) state that factor loadings higher than 0.35 are adequate with the sample size of this research; moreover, Stevens (1992) suggests cut-off criteria of 0.4 irrespective of sample size. Particularly, following the Hair et al. (1998) criteria for assessing the practical significance, factor loadings higher than 0.3 (with a sample of 350 respondents) or 0.35 (with a sample of 250 respondents), are considered significant. In our research, the factor loadings are all above 0.5 with a sample size is of 310 respondents. Thus, all the factor loadings are adequate.

The EFA was confirmed by the KMO test $(0.834)$ and Bartlett test $(p$-value $=0.000)$ (Figure 2).

The relations amongst the variables and the hypotheses were tested through SEM. The maximum likelihood method was used for parameters estimation.

Threshold levels were assessed by Hu and Bentler (1999), who suggested a two-index presentation format. This always includes the SRMR with the NNFI (TLI), RMSEA or the CFI. Kline (2005) states that the Chi-square test, the RMSEA, the CFI and the SRMR indices should be observed. Hence, this research adopts these four indicators. In particular, in recent

Table 3.

AVE and CR values

\begin{tabular}{lcc}
\hline Factor & AVE & CR \\
\hline Attitude (ATT) & 0.771 & 0.910 \\
Social norms (SN) & 0.659 & 0.853 \\
Perceived behavioural control (PBC) & 0.540 & 0.776 \\
Intention (INT) & 0.721 & 0.885 \\
Environmental aspects (EA) & 0.520 & 0.764 \\
Inhibitors (IN) & 0.549 & 0.781 \\
\hline
\end{tabular}

Figure 2.

CFA
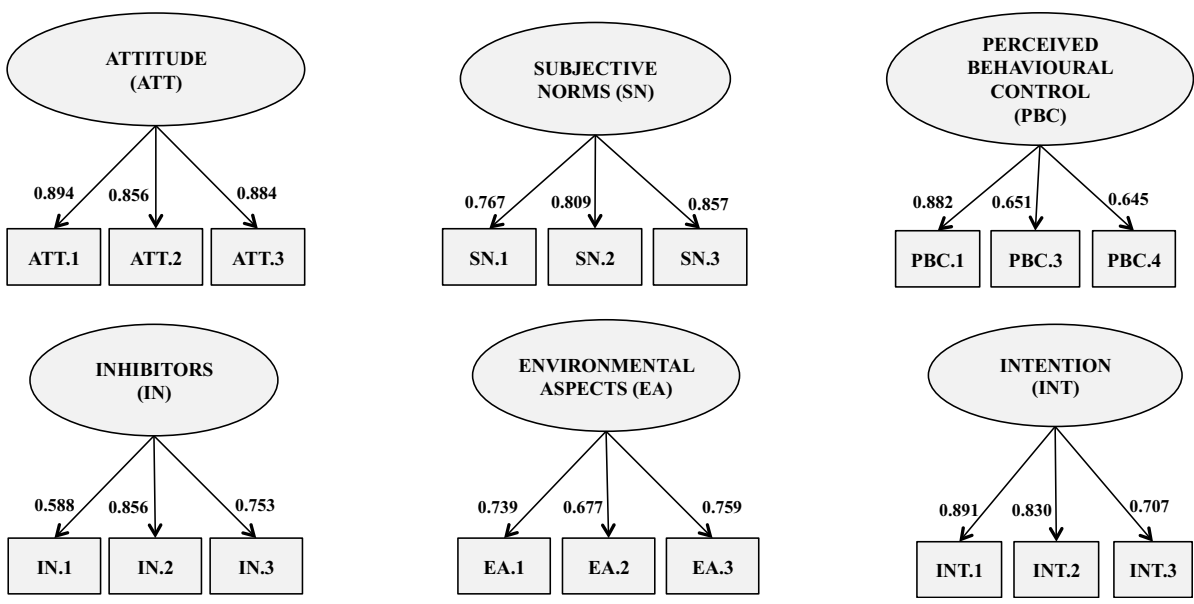
years the RMSEA has become regarded as "one of the most informative fit indices" (Diamantopoulos et al., 2000) illustrating how well the model, with unknown but optimally chosen parameter estimates, would fit the populations' covariance matrix (Byrne, 1998).

The results are shown in the following table. Observed goodness of fit parameters is reported in Table 5, while the graphical representation of the complete model in Figure 3.

It is possible to observe that the model has been supported, although it has to be noted that the $H 3$ is not significant; thus, the attitude does not affect the intention ( $H 3$ rejected). This can be due to the fact that people are not able to realise or imagine how to use an automated car. Thus, this can imply that their attitude is not fully formed yet. The possible theoretical explanation of the absence of relation between attitude and intention is described in section "Research model and hypotheses". In this regard, it can be due to "contingent consistency" (Susmilch et al., 1975; Andrews and Kandel, 1979; Acock and DeFleur, 1972; Liska, 1974, 1984; Warner and DeFleur, 1969), which states that attitude not necessarily influences the intentions, as there could be situational conditions can interact with attitude.

On this strength, we tested this model (H1, H2, H4 and H5). Following in Table 6, the goodness of fit and the graphical representation of the model (Figure 4) are illustrated.

As Table 7 and Figure 4 show, the research hypotheses $H 1, H 2, H 4$ and $H 5$ are supported. The data support the model structure in the absence of the attitude, as the goodness of fit indicators is located within the acceptable thresholds suggested by the literature. Hence, by applying the TPB in automotive 4.0, we notice that the main antecedents are: subjective norms, perceived behavioural control, inhibitors and environmental aspects.

The theoretical model and the related hypotheses are supported (Table 7).

\section{Discussions}

This paper applies the TPB to the context of automotive 4.0. In this way, it extends the TPB model by adding two more variables in affecting the intention to use high-tech automated vehicles, such as inhibitors and environmental aspects. Furthermore, the attitude does not

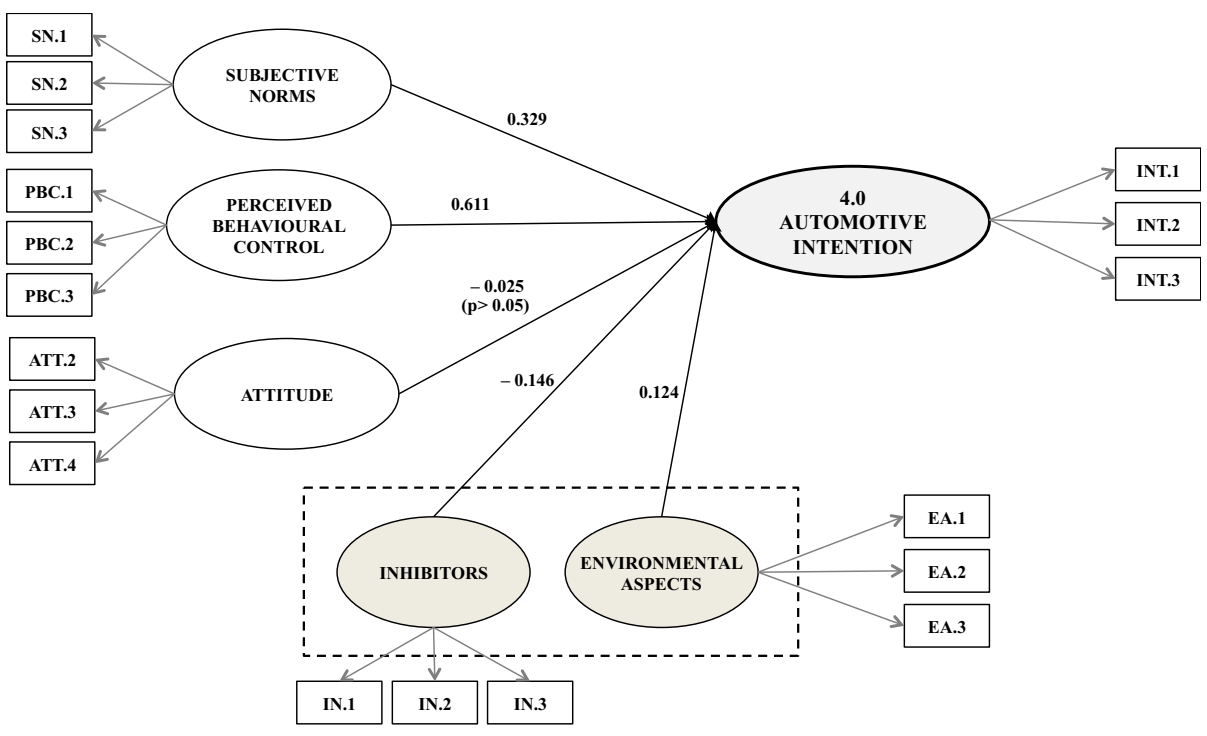

Automotive sector

573
Figure 3. Graphical representation of the model 
IJQSS

13,4

\begin{tabular}{|c|c|c|c|c|c|}
\hline & & & Factors & & \\
\hline Variables & 1 & 2 & 3 & 4 & 5 \\
\hline ATT2 & 0.835 & & & & \\
\hline ATT1 & 0.829 & & & & \\
\hline ATT3 & 0.796 & & & & \\
\hline EA1 & & 0.959 & & & \\
\hline EA2 & & 0.866 & & & \\
\hline EA3 & & 0.558 & & & \\
\hline SN3 & & & 0.833 & & \\
\hline SN1 & & & 0.734 & & \\
\hline SN2 & & & 0.666 & & \\
\hline IN3 & & & & 0.840 & \\
\hline IN1 & & & & 0.759 & \\
\hline IN2 & & & & 0.592 & \\
\hline $\mathrm{PBC} 2$ & & & & & 0.729 \\
\hline PBC3 & & & & & 0.614 \\
\hline PBC1 & & & & & 0.582 \\
\hline
\end{tabular}

Figure 4.

Graphical

representation of the model

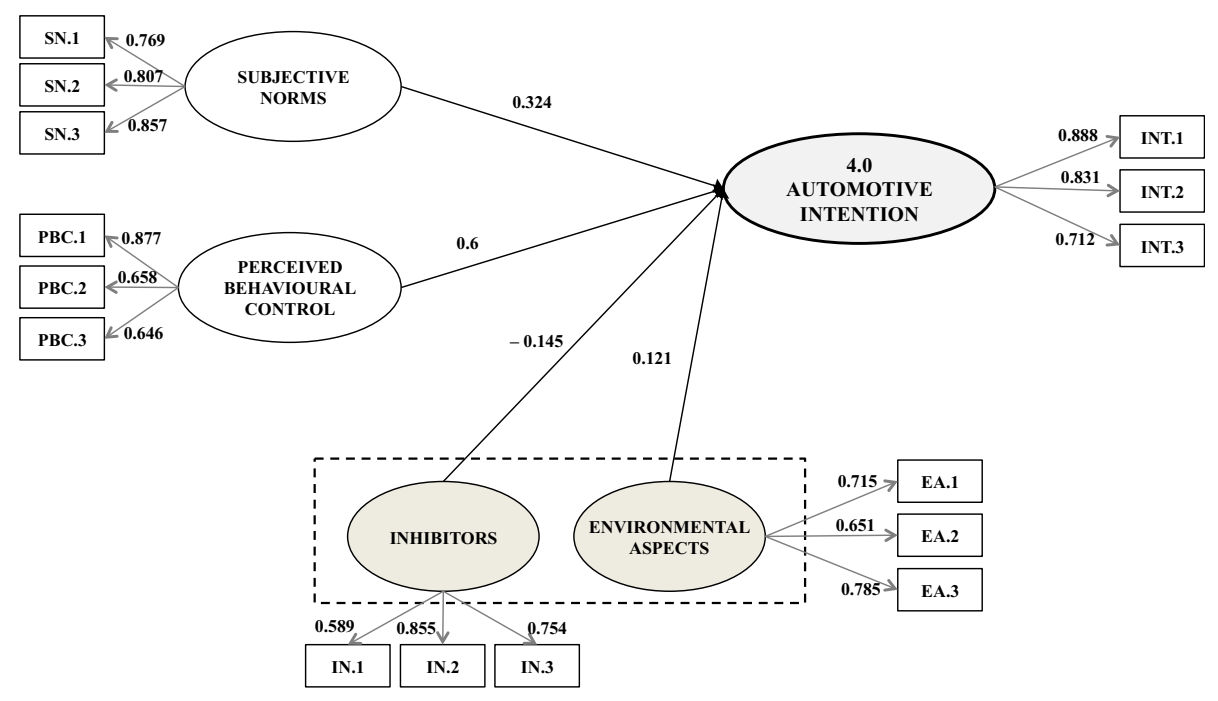

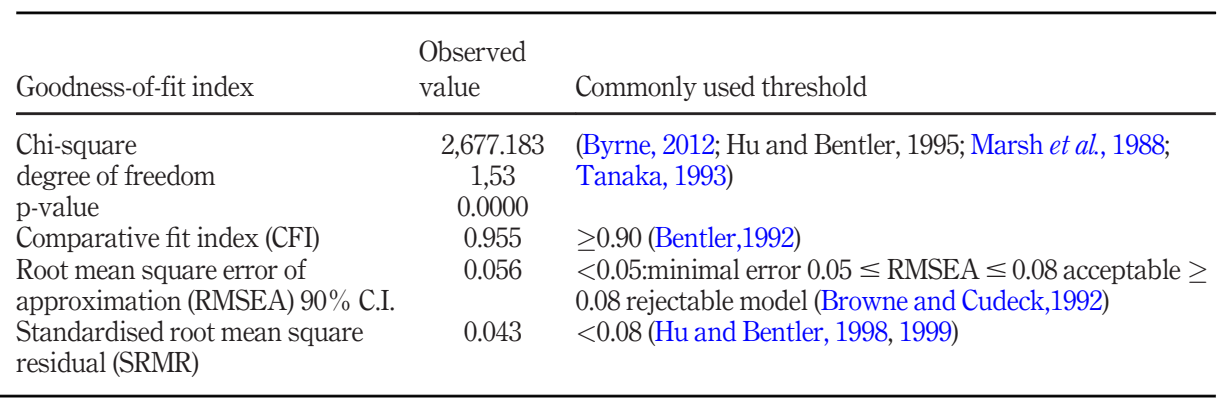

Table 5.

Goodness of fit

$$
\text { residual (SRMR) }
$$




\begin{tabular}{|c|c|c|c|}
\hline Goodness-of-fit index & $\begin{array}{l}\text { Observed } \\
\text { value }\end{array}$ & Commonly used threshold & sector \\
\hline $\begin{array}{l}\text { Chi-square } \\
\text { degree of freedom } \\
\text { p-value }\end{array}$ & $\begin{array}{l}1948.939 \\
105 \\
0.0000\end{array}$ & $\begin{array}{l}\text { (Byrne, 2012; Hu and Bentler, 1999; Marsh et al., } \\
\text { 1988; Tanaka,1993) }\end{array}$ & \\
\hline Comparative fit index (CFI) & 0.959 & $\geq 0.90$ (Bentler,1992) & \\
\hline $\begin{array}{l}\text { Root mean square error of approximation } \\
\text { (RMSEA) } 90 \% \text { C.I. }\end{array}$ & 0.056 & $\begin{array}{l}<0.05 \text { :minimal error } 0.05 \leq \text { RMSEA } \leq 0.08 \\
\text { acceptable } \geq 0.08 \text { rejectable model (Browne and }\end{array}$ & 575 \\
\hline $\begin{array}{l}\text { Standardised root mean square residual } \\
\text { (SRMR) }\end{array}$ & 0.045 & $\begin{array}{l}\text { Cudeck,1992) } \\
<0.08 \text { (Hu and Bentler, 1998, 1999) }\end{array}$ & $\begin{array}{r}\text { Table } 6 . \\
\text { Goodness of fit }\end{array}$ \\
\hline
\end{tabular}

\begin{tabular}{|c|c|c|c|c|c|c|c|}
\hline Hypotheses & Predictor & Dependent & Estimate & S.E. & Two-tailed value & Status & \\
\hline H1 & Subjective norm & Intention & 0.317 & 0.099 & 0.001 & Supported & \\
\hline $\mathrm{H} 2$ & Perceived behavioural control & Intention & 0.602 & 0.100 & 0.000 & Supported & \\
\hline H3 & Attitude & Intention & ${ }_{-}$ & - & - & Not supported & Table 7. \\
\hline $\mathrm{H} 4$ & Inhibitors & Intention & -0.146 & 0.049 & 0.003 & Supported & Status of research \\
\hline H5 & Environmental aspects & Intention & 0.113 & 0.051 & 0.025 & Supported & hypotheses \\
\hline
\end{tabular}

affect the intention and this might be probably due to "contingent consistency" as explained in consumer behaviour and research design and hypotheses sections. However, there could be other explanations, such as low awareness about how this kind of innovative solutions works. Indeed, although the attitude towards the behaviour reflects the individual's positive or negative evaluations of performing a particular behaviour, there could be conditions in which people are not willing to act (regardless of social pressures exist). The behaviour has not been included in this research model because, as suggested by the literature review, its results be challenging to measure, as very few people have experienced it.

This model explains that the intention to use high tech automated vehicle depends mainly (0.6) on perceived behavioural control that is the perceptions of their ability to use it; subjective norms also represents a relevant driver (0.324) in increasing the intention. Then, the perception of positive environmental (0.113) impacts of high-tech car adoption also improved the intention, whereas the Inhibitors $(-0.145)$ have a negative effect on the intention.

This research has both theoretical and managerial implications. Firstly, by using quantitative analysis, it empirically confirms the validity of the TPB model in the newest context, except for the attitude construct that seems not to be relevant in affecting the intention; hence, based on this model, to induce to adopt this technology, companies can promote/communicate the social acceptance, the related environmental benefit and its easy implementation/usage by potential customers; moreover, by reassuring potential users about the absence of risks and privacy concerns could enhance the willingness to adopt automated cars.Moreover, this research goes beyond the model, proposing a new version that includes two other ad hoc variables. The managerial implications concern the possibility of exploiting these results by policymakers, automotive companies and municipalities, as the insights of this research could be used to plan high-tech car launch consistently with potential users' needs. For instance, manufacturers need to consider environmental aspects and privacy issues during automotive 4.0 diffusion. 
IJQSS

13,4

In terms of limitations, this study has been conducted in Italy. Thus, other countries can be included, on the basis of different level of Industry 4.0 development. The questionnaire was administered to a convenience sample. The majority of respondents have been young people; further survey could include different age ranges to compare the behavioural patterns.

\section{Conclusions}

Increasing global urbanisation leads to discuss the ability to ensure the quality of life and sustainability within the urban area. The need to renew and develop urban infrastructure for this purpose is paving the way for the rise and expansion of Industry 4.0, which can affect the interaction between humans and machines. In this context, the automotive industry is currently undergoing a potentially revolutionary change, not only on transportation behaviour but also on the design of the urban infrastructure. Although Automotive 4.0 is at its inception, it will be established in the next years, mainly with two emerging trends in personal transportation: the already established on-demand mobility (car sharing) and the automated vehicles - A.V.s (self-driving or driverless vehicles). The first trend has been widely studied in the literature and consumers' behaviour antecedents (enablers and inhibitors) of car-sharing adoption can be measured through existing models. The A.V. needs to be further investigated and the empirical model still needs to be acknowledged. These newest trends of car-sharing and A.V. are enabled by technology, expected to replace (and support) human decision with computer algorithms.

The interest in automated driving is especially due to the potential implications in terms of safety and environmental impacts (European Commission, 2011). The activation of fully automated driving allows to drive vehicles autonomously without any intervention from the driver, enabling benefits for the society in terms of traffic reduction, resource efficiency (fuel consumption decrease) and decrease of pollution, implying also driving comfort for the drivers (Saad and Villame, 1996).

This research fills existing gaps, as prior studies did not commonly focus on the users' attitudes and intention towards automated cars in terms of judging perceived benefits and concerns (König and Neumayr, 2017). Indeed, besides obvious benefits, there are concerns and situational conditions that can inhibit an a priori acceptability of new technology.

As the TPB model confirms the intention to use automated vehicles depends on perceived behavioural control and Subjective norms, whereas the attitude does not influence the intention. Indeed, even though people may find an action appealing, they could intend not to act regardless of the social pressures and the feasibility of acting. As Bagozzi (1992) suggests, further research could try to understand whether attitudes may first be translated into desires to affect the intentions to act (and as a consequence, the behaviour).

Furthermore, environmental aspects (the ability of the technology to reduce environmental impacts and protect the environment) and inhibitors (danger for the driver, privacy issues, loss of control) are two new constructs - emerged in literature - that have been confirmed as significant.

In particular, this study extends the TPB, applying it to automotive 4.0. The proposed model was empirically confirmed, revealing that the intention of using A.V. depends on the behaviour of other relevant people (subjective norms), the perceived feasibility of using it (perceived behavioural control), the absence (or low presence) of risk and privacy concerns, the possibility to reduce the environmental impacts. The attitude does not affect the intention in this phase of diffusion. There could be other explanations, such as low awareness about how this kind of innovative solutions works. Indeed, as the "contingent consistency" state, although the attitude towards the behaviour reflects the individual's 
positive or negative evaluations of performing a particular behaviour, there could be social and situational conditions in which people are not willing to act; and this explains the case in which the attitude does not affect the intention. As automated cars are new on the market and very few experienced them, the lack of knowledge and awareness could also contribute to this result.

Indeed, this study has both theoretical and managerial implications. The first concerns potential areas of research to be explored. As it is still unknown what the key "drivers" or determinants of automated driving are, there is a need for more research on user acceptance or interest in automated driving - including results from different countries. Cultural differences can represent an important lens of observation because the country of origin can influence the acceptance; also, comparing people living within the urban area with whom are living in the suburbs can provide insights on different behaviour. On this strength, it could be relevant to replicate the study once this technology will start to be widely adopted, to observe whether the attitude is significant in explaining the intention and the behaviour.

It has to be noted that as Böhm et al. (2006) and Glancy (2012) state, despite the potential benefits of automotive 4.0, the level of adoption depends on the user's characteristics and on their preference between "moving" and "being moved". Consistently, driving enthusiasts use to drive cars for pleasure. Thus, they might not be amongst the people adopting this new technology.

Given the relevant consequences and benefits of the acceptance and diffusion of autonomous vehicles, it is crucial to understand all the potential antecedents and obstacles to its usage. This is useful to pave the way to its concrete diffusion by acquiring insights on production planning, customers' needs, urban setting, further services to be included.

Another possible area of research is the link between the two emerging trends of Automotive 4.0: car sharing and A.V.; as car sharing is strongly adopted, could be relevant to understanding whether its adoption facilitates the intention to use automated cars or also whether people will be willing to adopt an autonomous shared vehicle instead of owning it. From the users perspective, the importance of technological readiness in revealing the willingness of A.V. acceptance could be another area of research. Furthermore, other research studies could shed light on the changes due to high-tech cars diffusion at the urban level, understanding the consequences in terms of transportation patterns (private vehicles, public transport and car-sharing).

In terms of managerial implications, it has to be noted that the increasing attention towards environmental protection could represent a lever for automated car diffusion. Indeed, environmental benefits deriving from this kind of technology are confirmed; thus, it is crucial to communicate them accurately. Automated cars could be planned to control and optimise energy consumption by using advanced technologies that choose the most resources efficient path. The result is improved energy use, reduction of traffic congestion and lower environmental impacts. This topic is essential for society, communities' wellbeing and for achieving the Agenda 2030 sustainable development goals. Hence, an incentive framework could promote and inform about the advantages of automated car for users, community, countries. This could contribute to creating a positive attitude towards automated cars.

To spread this innovation, it is vital to achieving a wide number of users; this will demonstrate the feasibility to use and its suitability to everyone, which will lead further people to adopt it. Further practical research needs to understand issues that still represent inhibitors to automated cars adoption: potential danger for the driver, privacy issues and possible loss of control and distraction. Companies need to demonstrate that they are managing these risks and that they are able to avoid them. To accept this technological 
innovation and to appreciate the related advantages listed above, appropriate communication about benefits and risks management needs to be conducted to improve the perception of its reliability.

\section{References}

Acock, A.C. and DeFleur, M.L. (1972), "A configurational approach to contingent consistency in the attitude-behaviour relationship", American Sociological Review, Vol. 37 No. 6, pp. 714-726.

Ajzen, I. (1987), "Attitudes, traits, and actions: dispositional prediction of behaviour in personality and social psychology", In Advances in Experimental Social Psychology, Vol. 20, Academic Press, pp. 1-63.

Ajzen, I. (1991), "The theory of planned behavior-organizational behavior and human decision processes 50. Ajzen, I.(2002) Perceived behavioural control, self-efficacy, locus of control and the theory of planned behaviour", Journal of Applied Social Psychology, Vol. 32 No. 4, pp. 665-683.

Ajzen, I.F. and Fishbein, M.M. (1980), “Understanding attitudes and predicting social behaviour”.

Ajzen, I. and Madden, T.J. (1986), "Prediction of goal-directed behaviour: attitudes, intentions, and perceived behavioural control", Journal of Experimental Social Psychology, Vol. 22 No. 5, pp. 453-474.

Almada-Lobo, F. (2016), “The industry 4.0 revolution and the future of manufacturing execution systems (MES)", Journal of Innovation Management, Vol. 3 No. 4, pp. 16-21.

Anderson, J.M., Nidhi, K., Stanley, K.D., Sorensen, P., Samaras, C. and Oluwatola, O.A. (2014), "Autonomous vehicle technology: a guide for policymakers", Rand Corporation.

Andrews, K.H. and Kandel, D.B. (1979), "Attitude and behavior: a specification of the contingent consistency hypothesis", American Sociological Review, Vol. 44 No. 2, pp. 298-310.

Aria, E., Olstam, J. and Schwietering, C. (2016), "Investigation of automated vehicle effects on driver's behavior and traffic performance", Transportation Research Procedia, Vol. 15, pp. 761-770.

Arnold, C., Kiel, D. and Voigt, K.I. (2016), "How the industrial internet of things changes business models in different manufacturing industries", International Journal of Innovation Management, Vol. 20 No. 8, p. 1640015.

Bagozzi, R.P. (1981), “Attitudes, intentions, and behavior: a test of some key hypotheses”, Journal of Personality and Social Psychology, Vol. 41 No. 4, p. 607.

Bagozzi, R.P. (1992), "The self-regulation of attitudes, intentions, and behavior", Social Psychology Quarterly, Vol. 55 No. 2, pp. 178-204.

Baruch, J. (2016), "Steer driverless cars towards full automation”, Nature, Vol. 536 No. 7615, p. 127.

Bauer, W., Hämmerle, M., Schlund, S. and Vocke, C. (2015), “Transforming to a hyper-connected society and economy - towards an "industry 4.0", Procedia Manufacturing, Vol. 3, pp. 417-424.

Bauernhansl, T., Krüger, J., Reinhart, G. and Schuh, G. (2016), "Wgp-Standpunkt industrie 4.0, wissenschaftliche gesellschaft für produktionstechnik wgp”.

Beard-Gunter, A., Ellis, D.G. and Found, P.A. (2019), "TQM, games design and the implications of integration in industry 4.0 systems", International Journal of Quality and Service Sciences, Vol. 11 No. 2.

Becker, F. and Axhausen, K.W. (2017), "Literature Review on Surveys Investigating the Acceptance of Automated vehicles2, Transportation, Vol. 44 No. 6, pp. 1293-1306.

Begg, D. (2014), "A 2050 vision for london: what are the implications of driverless transport", available at: www.transporttimes.co.uk/Admin/uploads/64165-Transport-Times_A-2050Vision-for-London_AW-WEB-READY.pdf 
Beier, G., Niehoff, S., Ziems, T. and Xue, B. (2017), "Sustainability aspects of a digitalised industry - a comparative study from China and Germany", International Journal of Precision Engineering and Manufacturing-Green Technology, Vol. 4 No. 2, pp. 227-234.

Beiker, S.A. (2012), “Legal aspects of autonomous driving”, Santa Clara L. Rev, Vol. 52, p. 1145.

Bentler, P.M. (1992), "EQS structural equations program manual”, BMDP Statistical Software, Los Angeles.

Bezai, N.E., Medjdoub, B., Al-Habaibeh, A., Chalal, M.L. and Fadli, F. (2020), "Future cities and autonomous vehicles: analysis of the barriers to full adoption", Energy and Built Environment, Vol. 2 No. 1.

Böhm, S., Jones, C., Land, C. and Paterson, M. (2006), "Part one conceptualizing automobility: introduction: impossibilities of automobility", The Sociological Review, Vol. 54 No. s1, p. 1-16.

Brown, A., Gonder, J. and Repac, B. (2014), An Analysis of Possible Energy Impacts of Autonomous Vehicles. Road Vehicle Automation, in Meyer, G. and Beiker, S. (Eds), Springer. doi: 10.1007/9783-319-05990-7.

Browne, M.W. and Cudeck, R. (1992), "Alternative ways of assessing model fit", Sociological Methods and Research, Vol. 21 No. 2, pp. 230-258.

Buckley, L., Kaye, S.A. and Pradhan, A.K. (2018), "Psychosocial factors associated with intended use of automated vehicles: a simulated driving study", Accident Analysis and Prevention, Vol. 115, pp. 202-208.

Byrne, B.M. (1998), "Structural equation modeling with LISREL", PRELIMS and SIMPLIS: Basic Concepts, Applications and Programming, Lawrence Erlbaum Associates, Mahwah, NJ.

Byrne, B.M. (2012), "Structural equation modeling with mplus: basic concepts", Applications, and Programming, Routledge, New York, NY.

Chen, C.D., Fan, Y.W. and Farn, C.K. (2007), "Predicting electronic toll collection service adoption: an integration of the technology acceptance model and the theory of planned behavior", Transportation Research Part C: Emerging Technologies, Vol. 15 No. 5, pp. 300-311.

Collingwood, L. (2017), "Privacy implications and liability issues of autonomous vehicles", Information and Communications Technology Law, Vol. 26 No. 1, pp. 32-45.

Cronbach, L.J. (1951), "Coefficient alpha and the internal structure of tests", Psychometrika, Vol. 16 No. 3, pp. 297-334.

Davis, F.D. (1989), "Perceived usefulness, perceived ease of use, and user acceptance of information technology", MIS Quarterly, Vol. 13 No. 3, pp. 319-340.

Department for Transport (2016), "Department for transport annual report and accounts 2016-17".

Diamantopoulos, A., Siguaw, J.A. and Cadogan, J.W. (2000), "Export performance: the impact of crosscountry export market orientation. In american marketing association”, Conference Proceedings, American Marketing Association, Vol. 11, p. 177.

Douma, F. and Palodichuk, S.A. (2012), "Criminal liability issues created by autonomous vehicles", Santa Clara L. Rev, Vol. 52, p. 1157.

Eno Center. (2013), "Preparing a nation for autonomous vehicles: opportunities, barriers and policy recommendations", Eno Center for Transportation.

Etezadzadeh, C. (2015), "Smart City-Future City?: Smart City 2.0 as a Livable City and Future Market,", Springer.

European Commission (2011), "White paper: roadmap to a single european transport Area-Towards a competitive and resource-efficient transport system. COM", p. 144.

Fishbein, M.A. and Ajzen, I. (1975), Belief, Attitude, Intention and Behaviour: An Introduction to Theory and Research, Addison-Wesley, Reading. 
IJQSS

13,4

Folsom, T.C. (2012), "Energy and autonomous urban land vehicles", IEEE Technology and Society Magazine, Vol. 31 No. 2, pp. 28-38.

Fornell, C. and Larcker, D.F. (1981), "Evaluating structural equation models with unobservable variables and measurement error", Journal of Marketing Research, Vol. 18 No. 1, pp. 39-50, doi: 10.1177/002224378101800104.

Ghazizadek, M., Lee, J.D. and Boyle, L.N. (2012), "Extending the technology acceptance model to assess automation cognit. Technol”, Cognition, Technology and Work, Vol. 14 No. 1, pp. 39-49.

Glancy, D.J. (2012), "Privacy in autonomous vehicles", Santa Clara L. Rev, Vol. 52, p. 1171.

Goldenberg, J., Lehmann, D.R. and Mazursky, D. (2001), "The idea itself and the circumstances of its emergence as predictors of new product success", Management Science, Vol. 47 No. 1, pp. 69-84.

Greenblatt, J.B. and Shaheen, S. (2015), “Automated vehicles, on-demand mobility, and environmental impacts2”, Current Sustainable/Renewable Energy Reports, Vol. 2 No. 3, pp. 74-81.

Guglielmetti Mugion, R., Toni, M., Di Pietro, L., Pasca, M.G. and Renzi, M.F. (2019), “Understanding the antecedents of car-sharing usage. An empirical study in Italy", International Journal of Quality and Service Sciences, Vol. 11 No. 4.

Gummesson, E., Mele, C., Polese, F., Mele, C., Spena, T.R. and Colurcio, M. (2010), “Co-creating value innovation through resource integration”, International Journal of Quality and Service Sciences.

Hair, J.F., Tatham, R.L., Anderson, R.E. and Black, W. (1998), Multivariate Data Analysis, 5th Ed., Prentice-Hall, London.

Haustein, S. and Hunecke, M. (2007), "2Reduced use of environmentally friendly modes of transportation caused by perceived mobility necessities: an extension of the theory of planned behaviour”, Journal of Applied Social Psychology, Vol. 37 No. 8, pp. 1856-1883.

Heck, S. and Rogers, M. (2014), “Are you ready for the resource revolution”, McKinsey Quarterly, Vol. 2 , pp. 32-45.

Howard, D. and Dai, D. (2014), "Public perceptions of self-driving cars: the case of berkeley", $C A$, Presented at 93rd Annual Meeting of the Transportation Research Board, Washington, DC.

Hu, L.T. and Bentler, P.M. (1995), Evaluating model fit. in Hoyle, R.H. (Ed.), Structural Equation Modeling. Concepts, Issues, and Applications, Sage, London, pp. 76-99.

Hu, L.T. and Bentler, P.M. (1999), "Cut-off criteria for fit indexes in covariance structure analysis: conventional criteria versus new alternatives", Structural Equation Modeling: A Multidisciplinary Journal, Vol. 6 No. 1, pp. 1-55.

Hu, L.T. and Bentler, P.M. (1998), "Fit indices in covariance structure modeling: sensitivity to underparameterised model misspecification", Psychological Methods, Vol. 3 No. 4, pp. 424-453.

Hulse, L.M., Xie, H. and Galea, E.R. (2018), "Perceptions of autonomous vehicles: relationships with road users, risk, gender and age", Safety Science, Vol. 102, pp. 1-13.

Jiang, J.J., Muhanna, W.A. and Klein, G. (2000), "User resistance and strategies for promoting acceptance across system types", Information and Management, Vol. 37 No. 1, pp. 25-36.

Kemp, R., Schot, J. and Hoogma, R. (1998), "Regime shifts to sustainability through processes of niche formation: the approach of strategic niche management", Technology Analysis and Strategic Management, Vol. 10 No. 2, pp. 175-198.

Kiel, D., Müller, J., Arnold, C. and Voigt, K.I. (2017), "Sustainable industrial value creation: benefits and challenges of industry 4", International Journal of Innovation Management, Vol. 21 No. 8, p. 1740015.

Kline, R.B. (2005), Principles and Practice of Structural Equation Modeling, 2nd ed., The Guilford Press, New York, NY.

König, M. and Neumayr, L. (2017), "Users' resistance towards radical innovations: the case of the selfdriving car", Transportation Research Part F: traffic Psychology and Behaviour, Vol. 44, pp. $42-52$. 
Kopelias, P., Demiridi, E., Vogiatzis, K., Skabardonis, A. and Zafiropoulou, V. (2020), “Connected and autonomous vehicles-environmental impacts - a review", Science of the Total Environment, Vol. 712, p. 135237.

Automotive sector

Kyriakidis, M., Happee, R. and de Winter, J.C. (2015), "Public opinion on automated driving: results of an international questionnaire among 5000 respondents", Transportation Research Part F: traffic Psychology and Behaviour, Vol. 32, pp. 127-140.

Larue, G.S., Rakotonirainy, A., Haworth, N.L. and Darvell, M. (2015), "Assessing driver acceptance of intelligent transport systems in the context of railway level crossings", Transportation Research Part F: Traffic Psychology and Behaviour, Vol. 30, pp. 1-13.

Lasi, H., Fettke, P., Kemper, H.G., Feld, T. and Hoffmann, M. (2014), "Industry 4.0", Business and Information Systems Engineering, Vol. 6 No. 4, pp. 239-242.

Levinson, J., Askeland, J., Becker, J., Dolson, J., Held, D., Kammel, S., Kolter, J.Z., Langer, D., Pink, O., Pratt, V., Sokolsky, M., Stanek, G., Stavens, D., Teichman, A., Werling, M. and Thrun, S. (2011), "Towards fully autonomous driving: systems and algorithms", Intelligent Vehicles Symposium, Vol. 32 No. 14, pp. 163-168.

Liska, A.E. (1974), "Emergent issues in the attitude-behavior consistency controversy", American Sociological Review, Vol. 39 No. 2, pp. 261-272.

Liska, A.E. (1984), "A critical examination of the causal structure of the fishbein/ajzen attitude-behavior model”, Social Psychology Quarterly, Vol. 47 No. 1, pp. 61-74.

Malhotra, N.K. (1996), Marketing Research. Applied Orientation, Seconded, Prentice-Hall, Upper Saddle River N.J.

Marsh, H.W., Balla, J.R. and McDonald, R.P. (1988), "Goodness of fit indexes in confirmatory factor analysis: the effect of sample size”, Psychological Bulletin, Vol. 103 No. 3, pp. 391-410.

Milakis, D., Snelder, M., van Arem, B., van Wee, G.P., Correia, G.H. and de, A. (2017), "Development of automated vehicles in The Netherlands: scenarios for 2030 and 2050", EJTIR, Vol. 17, No. 1, p. 63-85.

Morrow, W.R., Greenblatt, J.B., Sturges, A., Saxena, S., Gopal, A., Millstein, D., Shah, N. and Gilmore, E.A. (2014), "Key factors influencing autonomous vehicles' energy and environmental outcome", in Meyer, G. and Beiker, S. (Eds), Road Vehicle Automation, Springer.

Nahtigal, M. and Bertoncelj, A. (2013), "Ownership restructuring in transition societies from historic perspective”, Acta Histrae, Vol. 21 No. 3, pp. 449-466.

Nielsen, T.A.S. and Haustein, S. (2018), On Sceptics and Enthusiasts: What Are the Expectations towards Self-Driving Cars?2, Transport Policy, Vol. 66, pp. 49-55.

Nordhoff, S., van Arem, B. and Happee, R. (2016), "Conceptual model to explain, predict, and improve user acceptance of driverless podlike vehicles", Transportation Research Record: Journal of the Transportation Research Board, Vol. 2602 No. 1, pp. 60-67.

Nunnally, J.C. (1978), Psychometric Theory, second ed. McGraw-Hill, New York.

Oviedo-Trespalacios, O., Nandavar, S. and Haworth, N. (2019), "How do perceptions of risk and other psychological factors influence the use of in-vehicle information systems (IVIS)?", Transportation Research Part F: traffic Psychology and Behaviour, Vol. 67, pp. 113-122.

Parasuraman, A. (2010), “Service productivity, quality and innovation”, International Journal of Quality and Service Sciences, Vol. 2 No. 3.

Payre, W., Cestac, J. and Delhomme, P. (2014), "Intention to use a fully automated car: attitudes and a priori acceptability”, Transportation Research Part F: traffic Psychology and Behaviour, Vol. 27, pp. 252-263.

Pejic" Bach, M., Zoroja, J. and Bosilj Vukšić, V. (2013), "Review of corporate digital divide research: a decadal analysis (2003-2012)" International Journal of Information Systems and Project Management, Vol. 1 No. 4, pp. 41-55. 
IJQSS

13,4

Polese, F., Vesci, M., Troisi, O. and Grimaldi, M. (2019), "Reconceptualising TQM in service ecosystems: an integrated framework", International Journal of Quality and Service Sciences, Vol. 11 No. 1.

Porter, M.E. and Heppelmann, J.E. (2014), "How smart connected products are transforming competition”, Harvard Business Review, Vol. 92, pp. 64-88.

Rahman, M.M., Lesch, M.F., Horrey, W.J. and Strawderman, L. (2017), “Assessing the utility of TAM, TPB, and UTAUT for advanced driver assistance systems", Accident Analysis and Prevention, Vol. 108, pp. 361-373.

Rojko, A. (2017), "Industry 4.0 concept: background and overview", International Journal of Interactive Mobile Technologies, Vol. 11 No. 5.

Reisinger, Y. and Turner, L. (1999), "Structural equation modeling with Lisrel: application in tourism", Tourism Management, Vol. 20 No. 1, pp. 71-88.

Roman, R., Zhou, J. and Lopez, J. (2013), "On the features and challenges of security and privacy in distributed internet of things", Computer Networks, Vol. 57 No. 10, pp. 2266-2279, doi: 10.1016/j. com- net.2012.12.018.

Saad, F. and Villame, T. (1996), "Assessing new driving support systems: contribution of an analysis of drivers' activity in real situations", In Proceedings of Third Annual World Congress on Intelligent Transport System (CD Rom).

SAE On-Road Automated Vehicle Standards Committee (2018), Taxonomy and Definitions for Terms Related to Driving Automation Systems for on-Road Motor Vehicles, SAE International: Warrendale, $P A$.

Schlechtendahl, J., Keinert, M., Kretschmer, F., Lechler, A. and Verl, A. (2015), "Making existing production systems industry 4.0-ready", Production Engineering, Vol. 9 No. 1, pp. 143-148.

Schoettle, B. and Sivak, M. (2014), "A survey of public opinion about autonomous and Self-Driving vehicles in the US, U.K., and Australia”, Report UMTRI-2014-21, University of MI, Ann Arbor.

Shladover, S.E. (2018), “Connected and automated vehicle systems: introduction and overview”, Journal of Intelligent Transportation Systems, Vol. 22 No. 3, pp. 190-200.

Silberg, G., Wallace, R., Matuszak, G., Plessers, J., Brower, C. and Subramanian, D. (2012), "Selfdriving cars: the next revolution, white paper", KPMG LLP and Center of Automotive Research, Vol. 36.

Song, C., Qu, Z., Blumm, N. and Barabási, A.L. (2010), "Limits of predictability in human mobility", Science, Vol. 327 No. 5968, pp. 1018-1021.

Stevens, J.P. (1992), Applied Multivariate Statistics for the Social Sciences, 2nd ed., Erlbaum, Hillsdale, NJ.

Susmilch, C.E., Elliott, G.C. and Schwartz, S.H. (1975), "Contingent consistency and the attitudebehavior relationship: a comment”, American Sociological Review, Vol. 40 No. 5, pp. 682-686.

Taeihagh, A. and Lim, H.S.M. (2019), "Governing autonomous vehicles: emerging responses for safety, liability, privacy, cybersecurity, and industry risks", Transport Reviews, Vol. 39 No. 1, pp. 103-128.

Tanaka, J.S. (1993), "Multifaceted conceptions of fit in structural equation models", in Bollen, K.A., Long, J.S. (Eds), Testing Structural Equation Models, Sage, Newbury Park, CA.

Terrade, F., Pasquier, H., Reerinck-Boulanger, J., Guingouain, G. and Somat, A. (2009), "L'acceptabilité sociale: la prise en compte des déterminants sociaux dans l'analyse de l'acceptabilité des systèmes technologiques", Le Travail Humain, Vol. 72 No. 4, pp. 383-395.

Troppe, W. (2014), "Energy implications of autonomous vehicles: imagining the possibilities", RMI Outlet (blog), Rocky Mountain Institute, available at: http://blog.rmi.org/ blog_2014_09_09_energy_implications_of_autonomous_vehicles 
Van Geenhuizen, M. and Nijkamp, P. (2003), "Coping with uncertainty: an expedition into the field of new transport technology", Transportation Planning and Technology, Vol. 26 No. 6, pp. 449-467.

Wadud, Z., MacKenzie, D. and Leiby, P. (2016), "Help or hindrance? The travel, energy and carbon impacts of highly automated vehicles", Transportation Research Part A: Policy and Practice, Vol. 86, pp. 1-18.

Walker, G.H., Stanton, N.A. and Young, M.S. (2001), “Where is computing driving cars?”, International Journal of Human-Computer Interaction, Vol. 13 No. 2, pp. 203-229.

Warner, L.G. and DeFleur, M.L. (1969), "Attitude as an interactional concept: social constraint and social distance as intervening variables between attitudes and action", American Sociological Review, Vol. 34 No. 2, pp. 153-169.

Wynstra, F., Spring, M. and Schoenherr, T. (2015), "Service triads: a research agenda for buyersupplier-customer triads in business services", Journal of Operations Management, Vol. 35 No. 1, pp. 1-20.

Yi, M.Y., Jackson, J.D., Park, J.S. and Probst, J.C. (2006), "Understanding information technology acceptance by individual professionals: towards an integrative view", Information and Management, Vol. 43 No. 3, pp. 350-363.

Zhao, J., Liang, B. and Chen, Q. (2018), “The key technology toward the self-driving car”, International Journal of Intelligent Unmanned Systems, Vol. 6 No. 1.

Zmud, J., Sener, I.N. and Wagner, J. (2016), "Self-driving vehicles: determinants of adoption and conditions of usage", Transportation Research Record: Journal of the Transportation Research Board, Vol. 2565 No. 1, pp. 57-64.

\section{Further reading}

Anania, E.C., Rice, S., Walters, N.W., Pierce, M., Winter, S.R. and Milner, M.N. (2018), "The effects of positive and negative information on consumers' willingness to ride in a driverless vehicle", Transport Policy, Vol. 72, pp. 218-224.

Bohm, D. and Hiley, B.J. (2006), The Undivided Universe: An Ontological Interpretation of Quantum Theory, Routledge.

Gabriel, M. and Pessl, E. (2016), "Industry 4.0 and sustainability impacts: critical discussion of sustainability aspects with a special focus on future of work and ecological consequences", Annals of the Faculty of Engineering Hunedoara, Vol. 14 No. 2, p. 131.

Kaur, K. and Rampersad, G. (2018), "Trust in driverless cars: Investigating key factors influencing the adoption of driverless cars", Journal of Engineering and Technology Management, Vol. 48, pp. 87-96.

Milonakis, D., Snelder, M., van Arem, B., van Wee, B. and de Almeida Correia, G.H. (2017), "Development and transport implications of automated vehicles in The Netherlands: scenarios for 2030 and 2050", European Journal of Transport and Infrastructure Research, Vol. 17 No. 1.

Oviedo-Trespalacios, O., Briant, O., Kaye, S.A. and King, M. (2020), "Assessing driver acceptance of technology that reduces mobile phone use while driving: the case of mobile phone applications", Accident Analysis and Prevention, Vol. 135, p. 105348.

Templeton, B. (2012), "Where robot cars (robocars) can really take us", Brad Templeton Robocar Blog. $N p$, available at: www.templetons.com/brad/robocars

\section{About the authors}

Martina Toni (martina.toni@uniroma3.it) is a Research Fellow, Department of Business Studies, University of Roma Tre, Italy. She has a $\mathrm{PhD}$ in Innovation, Quality and Sustainability. She is interested in, sustainability and innovation applied in different contexts such as tourism, transport and cultural heritage. She studies the opportunities and issues of emerging consumption patterns and 
IJQSS

13,4

the sharing economy phenomenon. She is involved in many research projects related to customer satisfaction, experience and behaviour. Martina Toni is the corresponding author and can be contacted at:martina.toni@uniroma3.it

Maria Francesca Renzi (mariafrancesca.renzi@uniroma3.it) is a Full Professor in the Department of Business Studies at Roma Tre University. She teaches Quality Management, Corporate Social Responsibility and Quality Systems. Her areas of interest involve quality management in the public and private sectors, service quality, quality and environmental management systems and corporate social responsibility. In these fields, she has published 92 scientific contributions. She serves as coordinator of many national and international research projects related to TQM diffusion. She is involved in several national committees as a quality assessor. She is a member of the Italian Academy of Commodity Science.

Maria Giovina Pasca (mariagiovina.pasca@uniroma3.it) is a PhD student in Quality, Innovation and Sustainability, Department of Business Studies, University of Roma Tre, Italy. Her research interests focus on total quality management, corporate social responsibility, sharing economy and gamification phenomenon applied in several contexts such as transport and tourism. She is a member of the Italian Academy of Commodity Science.

Roberta Guglielmetti Mugion (roberta.guglielmettimugion@uniroma3.it) is an Assistant Professor, Department of Business Studies, University of Roma Tre, Italy. She has a PhD in Commodity Science and is interested in quality management and sustainability applied in the private and public sector, quality in the food sector, quality and innovation, corporate social responsibility and cultural heritage management. In particular, she focusses on citizens' satisfaction. She is the coordinator and member of many research projects related to the TQM diffusion and cultural heritage management system. She is part of the Italian Academy of Commodity Science.

Laura Di Pietro (laura.dipietro@uniroma3.it) is an Assistant Professor, Department of Business Studies, University of Roma Tre, Italy. She holds a $\mathrm{PhD}$ in Commodity Science and Quality Management and teaches Corporate Social Responsibility and Quality Management. She is interested in TQM, service innovation and CSR topics applied in different sectors (e.g. cultural heritage and tourism, public services, health care, transport). In particular, she is interested in the study of methods and tools to measure customer satisfaction related to innovative services and sustainability. She is involved in many research projects in the public and private sector. She is a member of the Italian Academy of Commodity Science.

Veronica Ungaro (veronica.ungaro@uniroma3.it) is a $\mathrm{PhD}$ student in Quality, Innovation and Sustainability, Department of Business Studies, University of Roma Tre, Italy. She is interested in quality management, sustainability, corporate social responsibility, service quality and innovation applied in different sectors such as health care, transport and tourism. She is a member of the Italian Academy of Commodity Science.

For instructions on how to order reprints of this article, please visit our website: www.emeraldgrouppublishing.com/licensing/reprints.htm Or contact us for further details: permissions@emeraldinsight.com 